\title{
Pendugaan Bobot Badan Menggunakan Ukuran-Ukuran Tubuh pada Domba Wonosobo
}

\section{Estimation of Body Weight Using Body Measurements on Wonosobo Sheep}

\author{
Y. Haryanti, E. Kurnianto dan C.M.S. Lestari \\ Fakultas Peternakan dan Pertanian Universitas Diponegoro, Semarang \\ yuniharyay@gmail.com, kurniantoedy17@gmail.com
}

\begin{abstract}
The objective of this study was to estimate body weight of Wonosobo sheep using body measurements (Chest girth, shoulder height and body length). Two hundred seventy three of Wonosobo sheep consisting of 118 rams and 155 ewes grouped into 6 age groups (0-6 months, 7-11 months, 1-1.5 years, from 1.75 to 2 years, $2.5-3$ years and 3-4 years). Data were analyzed using proc stepwise (SAS version 6.12). The results showed chest girth and body length are important variables to predict body weight of Wonosobo sheep. Chest girth and body length have $90.97 \%$ and $76.09 \%$ contribution of the changes in body weight of rams and ewes. The conclusion of the study were chest girth and body length can be used to estimate body weight of Wonosobo sheep.
\end{abstract}

Key words : Body measurements, Body Weight, and Wonosobo sheep.

\begin{abstract}
ABSTRAK
Penelitian bertujuan untuk menduga bobot badan domba Wonosobo menggunakan ukuran-ukuran tubuh (lingkar dada, tinggi pundak dan panjang badan). Domba Wonosobo sebanyak 273 ekor yang terdiri dari 118 ekor domba jantan dan 155 ekor domba betina dikelompokkan menjadi 6 kelompok umur (0-6 bulan, 7-11 bulan, 1-1,5 tahun, 1,75-2 tahun, 2,5-3 tahun dan 3-4 tahun). Data yang diperoleh dianalisis menggunakan proc stepwise (SAS versi 6,12). Hasil penelitian menunjukkan lingkar dada dan panjang badan merupakan variabel yang sangat penting dalam menduga bobot badan domba Wonosobo. Lingkar dada dan panjang badan mempunyai kontribusi sebesar 90,97\% dan 76,09\% terhadap perubahan bobot badan domba jantan dan betina. Simpulan dari penelitian ini adalah lingkar dada dan panjang badan dapat digunakan untuk menduga bobot badan domba Wonosobo.
\end{abstract}

Kata kunci : Bobot badan, Domba Wonosobo, Ukuran-ukuran tubuh.

\section{PENDAHULUAN}

Domba Wonosobo merupakan domba hasil persilangan antara domba Ekor Tipis dan atau domba Ekor Gemuk dengan domba Texel asal Belanda (Menteri Pertanian, 2011) yang telah dikembangkan sejak tahun 1953 sebagai pengasil daging dan bulu di Kabupasten Wonosobo Jawa Tengah (Muryanto et al., 2010). Bobot badan (BB) domba Wonosobo jantan dapat mencapai $108 \mathrm{~kg}$ dengan lingkar dada (LD) 118,4 cm, panjang badan (PB) 106,2 $\mathrm{cm}$ dan tinggi pundak (TP) 77,6 cm sedangkan domba betina dapat mencapai $\mathrm{BB} 82 \mathrm{~kg}$ dengan LD 95,2 cm, PB $88 \mathrm{~cm}$ dan TP 72,2 cm (Menteri Pertanian, 2011).

Bobot badan merupakan aspek penting pada ternak karena dapat digunakan untuk menentukan kebutuhan pakan ternak dan kebutuhan jual beli ternak (Trisnawanto et al., 2012). Transaksi jual beli ternak di Jawa Tengah masih dilakukan dengan sistem pendugaan BB tanpa menimbang, sehingga banyak peternak yang rugi karena kesalahan pendugaan bobot badan 
(Basbeth, 2015). Penelitian mengenai pendugaan $\mathrm{BB}$ menggunakan ukuranukuran tubuh sudah banyak dilakukan pada beberapa jenis ternak seperti pada sapi (Ozkaya dan Bozkurt, 2009; Paputungan et al., 2013), kerbau (Paul dan Das, 2012), kuda (Takaendengan et al., 2012), kambing (Ojedapo et al., 2007; Bello dan Adama, 2012) dan domba (Birteeb dan Ozoje, 2012; Mahmud et al., 2014) dan domba Wonosobo jantan (Trisnawanto et al., 2012).

Tujuan penelitian ini adalah untuk menduga BB domba Wonosobo berdasarkan ukuran-ukuran tubuh. Manfaat penelitian ini adalah untuk mendapatkan rumus pendugaan $\mathrm{BB}$ domba Wonosobo.

\section{MATERI DAN METODE}

Penelitian dilaksanakan selama 8 bulan di Kecamatan Kejajar, Garung dan Mojotengah Kabupaten Wonosobo Jawa Tengah. Domba Wonosobo yang digunakan sebanyak 118 ekor jantan dan 155 ekor betina yang dikelompokkan berdasarkan umur (0-6 bulan, >6-12 bulan, $>12-18$ bulan, >18-24 bulan, >24-36 bulan dan $>36-48$ bulan).

Ukuran-ukuran tubuh diukur berdasarkan metode yang dilakukan Kutjoro et al. (2009) yaitu TP diukur dari bagian tertinggi gumba tegak lurus sampai tanah saat ternak berdiri normal menggunakan tongkat ukur, PB diukur berdasarkan jarak antara tepi depan sendi bahu benjolan tulang tapis menggunakan meteran, LD diukur melingkar rongga dada di belakang sendi tulang bahu menggunakan pita ukur. Bobot badan ditimbang menggunakan timbangan gantung kapasitas $150 \quad \mathrm{~kg}$ dengan ketelitian $0,05 \mathrm{~kg}$. Pengukuran ukuran tubuh dilakukan sebanyak 3 kali.

Data yang diperoleh dikelompokkan berdasarkan kelompok umur yang telah ditentukan serta dihitung rata-rata dan simpangan baku. Analisis menggunakan SAS versi 6.12 untuk menghitung persamaan regresi linear menggunakan proc stepwise.

\section{HASIL DAN PEMBAHASAN}

Rata-rata dan simpangan baku BB dan ukuran-ukuran tubuh domba disajikan pada Tabel 1. Berdasarkan Tabel 1 diketahui bahwa BB dan ukuran-ukuran tubuh domba jantan dan betina meningkat seiring dengan bertambahnya umur. Menurut Soeparno (2009) bobot badan ternak akan meningkat seiring dengan bertambahnya umur ternak itu sendiri. Badan badan dan ukuran tubuh domba domba Wonosobo hasil penelitian mengalami penurunan dibandingkan dengan BB dan ukuran-ukuran tubuh yang dilaporkan Menteri Pertanian (2011). Hal ini terjadi karena penurunan kualitas genetik domba yang diakibatkan masuknya pejantan dari bangsa lain (Muryanto et al., 2010). Domba jantan umur >36-48 bulan tidak ditemukan di lokasi penelitian karena domba pada umur tersebut telah dipotong atau dijual. 
Tabel 1. Rata-rata dan simpangan baku bobot badan dan ukuran-ukuran tubuh domba Wonosobo.

\begin{tabular}{lcccccc}
\hline $\begin{array}{c}\text { Umur } \\
\text { (bulan) }\end{array}$ & $\begin{array}{c}\text { Jenis } \\
\text { kelamin }\end{array}$ & Jumlah & $\begin{array}{c}\text { Bobot badan } \\
(\mathrm{kg})\end{array}$ & $\begin{array}{c}\text { Lingkar dada } \\
(\mathrm{cm})\end{array}$ & $\begin{array}{c}\text { Tinggi pundak } \\
(\mathrm{cm})\end{array}$ & $\begin{array}{c}\text { Panjang badan } \\
(\mathrm{cm})\end{array}$ \\
\hline $0-6$ & Jantan & 32 & $20,15 \pm 6,51$ & $61,48 \pm 7,99$ & $52,48 \pm 5,83$ & $53,97 \pm 6,91$ \\
& Betina & 25 & $23,56 \pm 4,25$ & $65,92 \pm 5,90$ & $52,25 \pm 4,64$ & $54,82 \pm 5,54$ \\
$>6-12$ & Jantan & 53 & $40,62 \pm 7,55$ & $78,58 \pm 5,95$ & $60,77 \pm 4,27$ & $65,89 \pm 5,64$ \\
& Betina & 25 & $35,72 \pm 3,58$ & $79,11 \pm 4,16$ & $60,10 \pm 4,39$ & $65,14 \pm 3,88$ \\
$>12-18$ & Jantan & 16 & $50,88 \pm 16,08$ & $84,45 \pm 10,85$ & $64,81 \pm 7,10$ & $72,11 \pm 9,82$ \\
& Betina & 25 & $35,11 \pm 7,34$ & $76,51 \pm 6,62$ & $57,24 \pm 9,76$ & $65,25 \pm 5,19$ \\
$>18-24$ & Jantan & 7 & $65,45 \pm 18,29$ & $98,19 \pm 15,91$ & $66,52 \pm 4,48$ & $73,19 \pm 10,67$ \\
& Betina & 31 & $39,09 \pm 7,49$ & $77,61 \pm 11,37$ & $59,74 \pm 4,44$ & $67,57 \pm 4,52$ \\
$>24-36$ & Jantan & 11 & $68,70 \pm 13,36$ & $95,75 \pm 9,81$ & $70,01 \pm 5,35$ & $73,49 \pm 6,29$ \\
& Betina & 31 & $42,48 \pm 12,20$ & $81,11 \pm 8,07$ & $60,41 \pm 3,37$ & $67,95 \pm 5,23$ \\
$>36-48$ & Jantan & - & - & & - & - \\
& Betina & 18 & $42,48 \pm 9,10$ & $80,47 \pm 7,13$ & $61,29 \pm 3,85$ & $68,97 \pm 4,44$ \\
\hline
\end{tabular}

Hasil analisis persamaan regresi menggunakan SAS versi 6.12 ditampilkan pada Tabel 2, Tabel 3 dan Tabel 4. Berdasarkan Tabel 2 diketahui bahwa LD merupakan variabel yang paling penting untuk menduga BB domba Wonosobo jantan. Variabel LD lebih baik digunakan bersamaan dengan PB untuk menduga bobot badan domba jantan pada umur 0-6 bulan, >12-18 bulan dan >18-24 bulan. Pada umur $>6-12$ bulan pendugaan bobot badan domba jantan lebih baik menggunakan LD, TP, dan PB, sedangkan pada umur >24-36 bulan variabel $L D$ dapat digunakan sendiri untuk menduga bobot badan

Tabel 2. Persamaan regresi ukuran-ukuran tubuh dengan bobot badan Domba Wonosobo jantan berdasarkan kelompok umur.

\begin{tabular}{llc}
\hline Umur (bulan) & \multicolumn{1}{c}{ Bentuk Persamaan Regresi } & $\mathrm{R}^{2}$ \\
\hline $0-6$ & $\mathrm{Y}=-25,384+0,740 \mathrm{LD}$ & 0,8266 \\
& $\mathrm{Y}=-27,822+0,517 \mathrm{LD}+0,299 \mathrm{~PB}$ & 0,8526 \\
\hline$>6-12$ & $\mathrm{Y}=-34,077+0,950 \mathrm{LD}$ & 0,5606 \\
& $\mathrm{Y}=-49,098+0,737 \mathrm{LD}+0,482 \mathrm{~PB}$ & 0,6621 \\
& $\mathrm{Y}=-60,172+0,664 \mathrm{LD}+0,401 \mathrm{TP}+0,366 \mathrm{~PB}$ & 0,6984 \\
\hline$>12-18$ & $\mathrm{Y}=-57,226+1,287 \mathrm{LD}$ & 0,7248 \\
& $\mathrm{Y}=-67,826+0,744 \mathrm{LD}+0,781 \mathrm{~PB}$ & 0,8288 \\
\hline$>18-24$ & $\mathrm{Y}=-41,407+1,081 \mathrm{LD}$ & 0,8978 \\
& $\mathrm{Y}=-75,697+1,087 \mathrm{LD}+0,464 \mathrm{~PB}$ & 0,9706 \\
\hline$>24-36$ & $\mathrm{Y}=-56,217+1,304 \mathrm{LD}$ & 0,9183 \\
\hline
\end{tabular}

Berdasarkan Tabel 3 diketahui bahwa LD merupakan variabel yang paling penting untuk menduga bobot badan domba Wonosobo betina pada umur 0-6 bulan, >18-24 bulan, >24-36 bulan, dan $>36-48$ bulan sedangkan TP merupakan variabel yang penting pada umur >6-12 bulan dan PB merupakan variabel yang paling penting pada domba umur >12-18 bulan. Lingkar dada dapat digunakan sendiri untuk menduga bobot badan domba betina pada umur 0-6 bulan dan >36-48 bulan. Pada domba betina umur $>12-18$ bulan, >18-24 bulan dan >24-36 bulan 
lingkar dada lebih baik digunakan dada lebih baik digunakan dengan tinggi bersamaan dengan panjang badan pundak.

sedangkan pada umur >6-12 bulan lingkar

Tabel 3. Persamaan regresi ukuran-ukuran tubuh dengan bobot badan Domba Wonosobo betina berdasarkan kelompok umur.

\begin{tabular}{llc}
\hline \multicolumn{1}{c}{ Umur (bulan) } & \multicolumn{1}{c}{ Bentuk Persamaan Regresi } & $\mathrm{R}^{2}$ \\
\hline $0-6$ & $\mathrm{Y}=-17,273+0,619 \mathrm{LD}$ & 0,7395 \\
\hline$>6-12$ & $\mathrm{Y}=7,252+0,473 \mathrm{TP}$ & 0,3375 \\
& $\mathrm{Y}=-10,543+0,271 \mathrm{LD}+0,412 \mathrm{TP}$ & 0,4312 \\
\hline$>12-18$ & $\mathrm{Y}=-37,570+1,113 \mathrm{~PB}$ & 0.6198 \\
& $\mathrm{Y}=-51,033+0,523 \mathrm{LD}+0.706 \mathrm{~PB}$ & 0.7602 \\
\hline$>18-24$ & $\mathrm{Y}=-36,843+0,958 \mathrm{LD}$ & 0.6358 \\
& $\mathrm{Y}=-64,166+0,788 \mathrm{LD}+0.603 \mathrm{~PB}$ & 0.7484 \\
\hline$>24-36$ & $\mathrm{Y}=-55,967+1,214 \mathrm{LD}$ & 0,6563 \\
& $\mathrm{Y}=-80,540+0,897 \mathrm{LD}+0,738 \mathrm{~PB}$ & 0,7019 \\
\hline$>36-48$ & $\mathrm{Y}=-35,038+0,965 \mathrm{LD}$ & 0,5676 \\
\hline
\end{tabular}

Berdasarkan Tabel 4 diketahui bahwa LD mempunyai peranan yang sangat penting untuk menduga bobot badan domba Wonosobo baik pada yang jantan maupun betina, namun penggunaanya dengan PB dapat memberikan hasil yang lebih baik. Nilai koefisien determinasi menunjukkan bahwa LD dan PB mempunyai kontribusi terhadap perubahan bobot badan domba jantan dan betina sebesar $90,97 \%$ dan $76,09 \%$.

Tabel 4. Persamaan regresi ukuran-ukuran tubuh dengan bobot badan Domba Wonosobo.

\begin{tabular}{clc}
\hline Jenis kelamin & \multicolumn{1}{c}{ Bentuk Persamaan Regresi } & $\mathrm{R}^{2}$ \\
\hline Jantan & $\mathrm{Y}=-54,759+1,230 \mathrm{LD}$ & 0,8935 \\
& $\mathrm{Y}=-62,957+1,011 \mathrm{LD}+0,389 \mathrm{~PB}$ & 0,9097 \\
\hline \multirow{2}{*}{ Betina } & $\mathrm{Y}=-43,961+1,042 \mathrm{LD}$ & 0,7129 \\
& $\mathrm{Y}=-53.479+0,763 \mathrm{LD}+0,477 \mathrm{~PB}$ & 0,7609 \\
\hline
\end{tabular}

Pesmen dan Yardimci (2008) menyatakan bahwa PB dan LD merupakan paramater yang paling sesuai untuk menduga bobot badan ternak. Malewa (2009) menyatakan bahwa LD mempunyai hubungan yang lebih erat dengan BB dibandingkan dengan PB. Penelitian Cam et al. (2010) pada domba Karayaka di Turki menunjukkan ukuran tubuh yang mempunyai korelasi positif dengan BB adalah dalam dada dan lingkar dada. Penelitian tersebut juga menunjukkan bahwa penggunaan dalam dada, tinggi pinggul, lingkar tulang canon, lebar dada, panjang badan dan lingkar dada lebih akurat dalam menduga bobot badan.

Hasil penelitian Birteeb dan Ozoje (2012) pada domba West African LongLegged dan West African Dwarf di Pong

4 | Pendugaan Bobot Badan Menggunakan Ukuran Ukuran Tubuh (Haryanti et al.) 
Tamale, Ghana menunjukkan untuk menduga bobot badan kedua bangsa domba tersebut variabel yang dibutuhkan adalah lingkar dada dan panjang badan. Hasil penelitian Younas et al. (2013) menunjukkan domba saat berumur 0-18 bulan, bobot badan berkorelasi dengan lingkar dada dan tinggi pundak, sedangkan ketika domba berumur $19-24$ bulan bobot badan berkorelasi oleh panjang badan dan tinggi pundak dan pada umur diatas 24 bulan bobot badan berkorelasi oleh tinggi pundak dan panjang badan. Mahmud et al. (2014) menyatakan bahwa menggunakan banyak variabel ukuran tubuh dapat meningkatkan keakuratan dalam menduga bobot badan ternak.

\section{KESIMPULAN}

Kesimpulan dari penelitian ini adalah lingkar dada dan panjang badan dapat digunakan untuk menduga bobot badan domba Wonosobo jantan dan betina.

\section{DAFTAR PUSTAKA}

Basbeth, A.B. 2015. Hubungan antara Ukuran-Ukuran Tubuh dengan Bobot Badan Kambing Jawarandu Jantan di Kabupasten Kendal Jawa Tengah. Fakultas Peternakan dan Pertanian, Universitas Diponegoro. (Skripsi Sarjana Peternakan).

Bello, A.A. and T.Z. Adama. 2012. Studies on body measurements of castrates and non-castrate Savannah
Brown goats. Asian J.Anim. Sci. 6(3):140-146.

Birteeb, P.T. and M.O. Ozoje. 2011. Prediction of live body weight from linear body measurements of West African Long-Legged and West African Dwarf sheep in Nothern Ghana. Online J. Anim. Feed. Res. 2(5):427-434.

Cam, M. A., M. Olfaz and E. Soydan. 2010. Body measurements reflect body weights and carcass yields in Karayaka sheep. Asian J. Anim. Vet. Adv. 5(2):120-127.

Kuntjoro, A., Sutarno dan O. P. Astirin. 2009. Body weight and statistic vital of Texel sheep in Wonosobo District by giving the ramie hay as an additional woof. Nusantara Bioscience. 1(1):23-30.

Mahmud, M.A., P. Shaba., W. Abdulsalam., H. Y. Yisa., J. Gana., S. Ndagi and R. Ndagimba. 2014. Live body weight estimation using cannon bone length and other body linear measurements in Nigerian breed of sheep. J. Adv. Vet. Anim. Res. 1(4):169-176.

Malewa, A. 2009. Penaksiran bobot badan berdasarkan lingkar dada dan panjang badan domba Donggala. J. Agroland. 16(1):91-97.

Menteri Pertanian. 2011. Penetapan Rumpun Domba Wonosobo. No: 2915/Kpts/OT.140/6/2011. Jakarta. Muryanto., D. Pramono, A. Widiyanto, Mahargono dan P. Saraswati. 2010. Dombos (Domba Wonosobo). 
Pemerintah Kabupaten Wonosobo.

Dinas Peternakan dan Perikanan Kabupaten Wonosobo. (Tidak diterbitkan).

Ojedapo, L.O., T.A. Adedeji, T.B. Olayeni, O.S. Adedeji, A.R. Abdullah and O.O. Ojebiyi. 2007. Influence of age and sex on body weight and some body measurements of extensively reared Wad goats in derived savannah zone of Nigeria. J. Anim. Vet. Adv. 6(1):114-117.

Ozkaya, S. and Y. Bozkurt. 2009. The acuuracy of prediction of body weight from body measurements in beef cattle. Arch. Tierz. 4 371-377.

Paputungan, U., L. Hakim., G. Ciptadi and H.F.N. Lapian. 2013. The estimation of live weight from metric body measurements in Ongole grade cows. J. Indonesian. Trop. Anim. Agric. 38(3):149 - 155. Paul, S.S. and K. S. Das. 2012. Prediciton of body weight from linear body measurements in Nili-Ravi buffalo calves. J. Buffalo Sci. 1:32-34.
Pesmen, G. and M. Yardimci. 2008. Estimating the live weight using some body measurements in Saanen goats. Archiva Zootechnica. 11(4):30-40.

Soeparno. 2009. Ilmu dan Teknologi Daging. Gadjah Mada University Press, Yogyakarta. Takaendengan, B.J., U. Papuntungan, R.R. Noor and S. Adiani. 2012. Live weight estimation by chest girth, body lenght, and body volume formula in Minahasa local horse. Media Perternakan. 35(2):80-84.

Trisnawanto, R., R. Adiwinarti dan W. S. Dilaga. 2012. Hubungan antara ukuran-ukuran tubuh dengan bobot badan dombos jantan. Anim. Agric. J. 1(1):653-668.

Younas, U., M. Abdullah, J. A. Bhatti, T. N. Pasha, N. Ahmad, M. Nasir and A. Hussain. 2013. Inter-relationship of body weight with linear body measurements in Hissardale sheep at different stages of life. J. Anim. Plant Sci. 23(1):40-44 